\title{
UTILIZAÇÃO DE FERRAMENTA ESTRATÉGICA NO CONTROLE DE ESTOQUE EM UNIDADES DE ALIMENTAÇÃO E NUTRIÇÃO
}

\author{
Use of strategic tools in stock control in food and nutrition units \\ Uso de herramientas estratégicas en el control de stock en alimentos y \\ unidades de nutrición
}

Andressa Giselle Gomes de Araújo - Nutricionista pela Faculdade de Ciências da Saúde do Trairí, Universidade Federal do Rio Grande do Norte - FACISA/UFRN • Email: andressagiselle7@hotmail.com

Franciane Pereira da Silva $\bullet$ Nutricionista pela Faculdade de Ciências da Saúde do Trairí, Universidade Federal do Rio Grande do Norte - FACISA/UFRN • E-mail: franciane.ciane.fp@gmail.com

Antônia Isabelly Monteiro dos Anjos • Nutricionista pela Faculdade de Ciências da Saúde do Trairí, Universidade Federal do Rio Grande do Norte - FACISA/UFRN • E-mail: isabelly_ikm@hotmail.com

Letícia Karin Dantas de Azevêdo - Nutricionista pela Faculdade de Ciências da Saúde do Trairí, Universidade Federal do Rio Grande do Norte - FACISA/UFRN • E-mail: leticiakarin1@hotmail.com

Mariana Silva Bezerra - Nutricionista - Doutoranda pelo Programa de PósGraduação em Saúde Coletiva da Universidade Federal do Rio Grande do Norte PPGScol/UFRN • E-mail: marianabezerrarn@gmail.com

Autora responsável pela correspondência:

Mariana Silva Bezerra. E-mail: marianabezerrarn@gmail.com 


\section{RESUMO}

Introdução: Há diferentes ferramentas para gerenciamento de estoque e ter um bom controle garantirá melhor resultado financeiro e qualidade dos produtos armazenados em um estabelecimento. Como por exemplo o sistema de custeio ABC que é um método eficaz e de baixo custo. Objetivo: Elaborar e analisar a curva $A B C$ de duas Unidades de Alimentação e Nutrição de um órgão federal do Rio Grande do Norte. Metodologia: Trata-se de um estudo de caso com delineamento descritivo, recorte transversal e abordagem quantitativa realizado em dois restaurantes universitários. Para a obtenção dos dados, houve a necessidade da análise dos cardápios semanais planejados para desjejum, almoço e jantar de ambas as entidades. O custo anual de cada gênero alimentício consumido nos restaurantes foi organizado em planilha no Microsoft Excel para cálculo do percentual individual e acumulado. Posteriormente foram elaboradas as curvas $\mathrm{ABC}$, de modo que itens com percentual acumulado até $80 \%$ foram classificados como A, de $80,01 \%$ e $95 \%$ como B e de $95,01 \%$ a $100 \%$ como C. Resultados: Foram identificados 198 gêneros alimentícios presentes no estoque do restaurante 1 e 111 presentes no restaurante 2. Na curva ABC do restaurante 1 foi encontrado na categoria A: 79,72\% (31 itens); na categoria B: $15,18 \%$ (49 itens); e na categoria C: 5,09\% (118 itens). No restaurante 2 na categoria A: 79,73\% (36 itens); categoria B: 15,21\% (36 itens); e categoria C: 5,06\% (39 itens). Conclusões: Devido as instituições serem de portes diferentes, as curvas $\mathrm{ABC}$ foram divergentes. Entretanto, alguns alimentos foram comuns, principalmente na categoria $\mathrm{A}$, composta por itens proteicos e de alto custo. Percebeu-se que para um gerenciamento adequado é necessário um controle de custos eficiente, o qual necessita da aplicação de sistemas de análise sobre as informações gerenciais disponibilizadas, como a curva ABC.

Palavras-Chave: Recursos; Serviços de Alimentação; Sistema de custos;

Armazenamento de Alimentos, Gestão de Estoques.

\section{ABSTRACT}

Introduction: There are different tools for managing inventory and having a good control will guarantee better financial results and quality of the products stored in an establishment. For example, the $\mathrm{ABC}$ costing system, since it is an effective and low cost method. Objective: Develop and analyze the ABC curve of two Food and Nutrition Units of a federal agency located in Rio Grande do Norte. Methodology: This is a case study with descriptive design, cross-sectional and quantitative approach performed in two University Restaurants. To obtain the data, it was necessary to analyze the weekly menus planned for breakfast, lunch and dinner for both entities. The annual cost of each foodstuff consumed in restaurants was organized in an Microsoft Excel spreadsheet to calculate the individual and accumulated percentage. Subsequently, the ABC curves were elaborated, so that items with an accumulated percentage of up to $80 \%$ were classified as $A, 80.01 \%$ and $95 \%$ as B and $95.01 \%$ to $100 \%$ C. Results: 198 foodstuffs present in the stock of Restaurant 1 and 111 present in staurant 2 were identified. On the ABC curve of restaurant 1, category A was found: $72 \%$ (31 items); Category B: 15.18\% (49 items); Category C: 5.09\% (118 items). In taurant 2 in category A: 79.73\% (36 items); Category B: 15.21\% (36 items); Category $5.06 \%$ (39 items). Conclusions: Because the institutions are of different sizes, the 
$\mathrm{ABC}$ curves were divergent. However, some foods were common, mainly in category A, consisting of protein items and high cost. It was noticed that for an adequate management it is necessary an efficient cost control, which requires the application of systems of analysis on the management information made available as the ABC curve.

Keywords: Resources; Food Services; Cost system; Food Storage, Inventory Management.

\section{RESUMEN}

Introducción: Existen diferentes herramientas para la gestión del inventario y tener un buen control garantizará mejores resultados financieros y la calidad de los productos almacenados en un establecimiento. Por ejemplo, el sistema de costeo ABC, que es un método efectivo y de bajo costo. Objetivo: Desarrollar y analizar la curva ABC de dos Unidades de Alimentos y Nutrición de una agencia federal ubicada en Rio Grande do Norte. Metodología: Este es un caso de estudio con diseño descriptivo, enfoque transversal y cuantitativo realizado en dos restaurantes universitarios. Para obtener los datos, fue necesario analizar los menús semanales planificados para el desayuno, el almuerzo y la cena para ambas entidades. El costo anual de cada alimento consumido en restaurantes se organizó en una hoja de cálculo Microsoft Excel para calcular el porcentaje individual y acumulado. Posteriormente, se elaboraron las curvas $\mathrm{ABC}$, de modo que los artículos con un porcentaje acumulado de hasta el $80 \%$ se clasificaron como A, del $80.01 \%$ y $95 \%$ B y del $95.01 \%$ al $100 \%$ C. Resultados: Se identificaron 198 alimentos presentes en el stock del Restaurante 1 y 111 presentes en el Restaurante 2. En la curva ABC del restaurante 1, se encontró la categoría A: 79.72\% (31 artículos); Categoría B: 15,18\% (49 artículos); Categoría C: 5.09\% (118 artículos). En el restaurante 2 de la categoría A: 79.73\% (36 artículos); Categoría B: 15,21\% (36 artículos); Categoría C: $5.06 \%$ (39 artículos). Conclusiones: Debido a que las instituciones son de diferentes tamaños, las curvas $\mathrm{ABC}$ eran divergentes. Sin embargo, algunos alimentos eran comunes, principalmente en la categoría $\mathrm{A}$, compuestos por elementos proteicos de alto costo. Se observó que para una gestión adecuada es necesario un control de costos eficiente, que requiere la aplicación de sistemas de análisis sobre la información de gestión disponible como la curva $A B C$.

Palabras clave: Recursos; Servicios de comida; Sistema de costos; Almacenamiento de alimentos; La gestión del inventario. 


\section{Introdução}

A gestão de suprimentos é descrita por um processo de integração que inicia no planejamento dos insumos e das quantidades que serão utilizadas, além da seleção e avaliação dos fornecedores, recebimento, armazenamento, produção e distribuição aos clientes. Seu objetivo é favorecer alta qualidade do produto, com baixo custo, sendo necessário adotar medidas de desempenho que harmonizem com as funções de cada tipo de serviço e aprimore os custos da produção ${ }^{1,2}$.

Muitas empresas trabalham com diferentes tipos de estoque e ter um bom controle irá garantir um resultado financeiro elevado e qualidade dos produtos armazenados dentro do estabelecimento, para isso, é necessário a eficiência e eficácia dos processos. Desse modo, o gerenciamento de estoque surge com a necessidade de controlar o fluxo de materiais como por exemplo: definir quais insumos são necessários para estocar, determinar a frequência e quantidade de reposição, acionar o setor de compras para aquisição, receber, armazenar, distribuir e controlar os materiais estocados e coordenar inventários constantes ${ }^{3,4}$.

Nesse contexto, em uma Unidade de Alimentação e Nutrição (UAN) aplica-se diversas estratégias no controle do estoque as quais irão se diferenciar entre cada unidade, sendo o mais comum e mais recomendado pela literatura o método "Primeiro que Entra, Primeiro que Sai" (PEPS) pois este permite a eliminação de insumos obsoletos. Além disso, um ponto crucial nesse cenário é atender um nível de estoque adequado para que não corra risco de ruptura, assim como não disponha de um elevado quantitativo que poderá ficar velho e posteriormente ser desprezado, o que implicará em custos explícitos com falhas do serviço e desperdício ${ }^{5}$.

Nesse âmbito, o custo de produção é composto por diversas variáveis, dentre elas encontram-se a mão de obra, água, gás, energia, aluguel, depreciação de equipamentos, material de limpeza e gêneros alimentícios. Este último apresenta uma contribuição orçamentária nesses serviços equivalente em média a $50 \%$, o que por sua ez demonstra um grau de importância elevado com relação ao processamento dessa atéria prima, resultando em minimização de custos e garantia de uma melhor lidade das refeições ${ }^{6}$. 
Diante do exposto, a aplicação eficaz da aquisição das matérias primas garante um controle e estabilidade da empresa no mercado. Assim, o gerenciamento das compras em UAN, seja privada ou pública, merece uma substancial atenção. No entanto, por envolver pregões eletrônicos e licitações, o setor público requer dessa gestão maior transparência na alocação dos recursos investidos - os quais apresentam restrição orçamentária - e que o serviço funcione com preços cada vez mais vantajosos ${ }^{7}$.

De maneira a auxiliar nesse contexto, o setor administrativo necessita de inúmeras estratégias e entre elas encontra-se a ferramenta da curva ABC. Esta consiste na classificação em ordem decrescente dos itens que apresentam maior relevância monetária no consumo e pedido de compra, demonstrando que alguns itens merecem maior destaque na administração do que outros, pois eles tendem a apresentar uma contribuição financeira superior ${ }^{8}$.

Assim, o gerenciamento de estoque pode ser realizado de maneira efetiva com o sistema de custeio $\mathrm{ABC}$, pois é um método eficaz e de baixo custo de aplicação. Na prática os gêneros classificados no item A são primordiais para a administração, os encontrados na categoria B apresentam-se em posição intermediária e os identificados como C são de menor importância financeira e baixa demanda. Apesar disso, a classe A possui menor quantidade de itens e a $\mathrm{C}$ aparece maior número de itens. Isso acontece inversamente com relação a contribuição financeira, a primeira classificação apresenta maior participação em percentual, a B média parcela e a última com menor percentual de influência financeira, sinalizando que poucos produtos possuem relevância maior com base na mobilização das finanças 9 .

O método $\mathrm{ABC}$ não é somente uma metodologia financeira ou de verificação de custos, mas uma ótima técnica de análise gerencial de estoque com o intuito de auxiliar nas decisões com utilização dos itens que possuem maior rotatividade e que apresenta maior rentabilidade para o estabelecimento. No entanto, os itens de menor aturamento não devem ser eliminados do seu estoque, pois agregam valor em lantidade e variedade de produtos ${ }^{10}$. 
As Unidades de Alimentação e Nutrição com características públicas e institucionais em geral possuem um perfil similar de clientela, cardápio (básico a intermediário) e gerenciamento de compras (licitação anual). No entanto, o porte de refeições pode ser divergente, o que pode resultar em um impacto significativo na quantidade de gêneros alimentícios utilizados. Dessa forma, surge como questionamento se há similaridade na composição e distribuição do estoque dessas UAN.

Posto isso, a identificação e classificação dos itens em estoque por meio da utilização da curva $\mathrm{ABC}$ irá nortear as decisões por parte da administração que não terá suas ações baseadas em métodos empíricos. E por sua vez, as unidades analisadas por funcionarem no setor público necessitam de um gerenciamento ainda mais minucioso para atender a produção com qualidade e limitação orçamentária. Desse modo, o estudo tem por objetivo elaborar e analisar a curva ABC de duas Unidades de Alimentação e Nutrição de um órgão federal situadas no Rio Grande do Norte.

\section{Metodologia}

Trata-se de uma pesquisa enquadrada em estudo de caso com delineamento descritivo, recorte transversal e abordagem quantitativa ${ }^{11}$ realizada em dois Restaurantes Universitários (RU), um sendo localizado na capital (RU1) e outro no interior (RU2) do estado do Rio Grande do Norte. A coleta de dados aconteceu no período de maio e junho no RU2 e outubro no RU1, ambos no ano de 2018.

Esses restaurantes fornecem diariamente em média 4150 refeições e 1200 refeições, respectivamente. O modelo de distribuição das refeições é do tipo self-service com porcionamento apenas das preparações ou alimentos proteicos. Usufruem de ambas unidades os estudantes da universidade, funcionários e no RU2 em associação, pacientes e acompanhantes de uma unidade hospitalar a qual o restaurante é vinculado.

A coleta de dados foi realizada durante o estágio curricular na área de gestão alimentação coletiva do curso de graduação em nutrição por meio da análise dos dápios planejados para o desjejum, almoço e jantar do domingo ao sábado de as as instituições, contudo a junção dessas informações ocorreu de forma distinta 


\section{ciência
piural}

em cada unidade. O RU1 possui um sistema digital utilizado diariamente pela UAN para controle de estoque, o Sistema Integrado de Patrimônio Administração e Contratos (SIPAC) que dispõe do quantitativo de todos os gêneros alimentícios utilizados no processo produtivo da unidade, a partir dessa ferramenta foi possível obter o consumo e o custo anual dos gêneros alimentícios para elaboração da curva ABC (Figura 1).

No entanto, a coleta de dados do RU2 se deu por meio de uma consulta aos documentos disponibilizados pela UAN, sendo eles: relatórios internos extraídos do sistema de gestão e controle e cardápio mensal. Obtendo os seguintes dados para a formulação da curva $\mathrm{ABC}$ : gênero alimentício, quantitativo do per capita utilizado, unidade de medida e custo. A partir desses dados foi calculado o consumo mensal e anual dos gêneros e, consequentemente, o custo anual (Figura 1).

Os respectivos dados foram coletados através de consulta a arquivos das instituições, as quais correspondem a dados de domínio público e que não identificam participantes de pesquisa, ou seja, não há qualquer envolvimento de seres humanos. Assim sendo, de acordo com a Resolução n ${ }^{\circ}$ 466/12 e a Resolução n ${ }^{\circ}$ 510/16 não há necessidade de registro e avaliação pelo Código de Ética em Pesquisa (CEP) 12,13. 
Figura 1 - Processamento de dados do estudo, Natal, 2018.

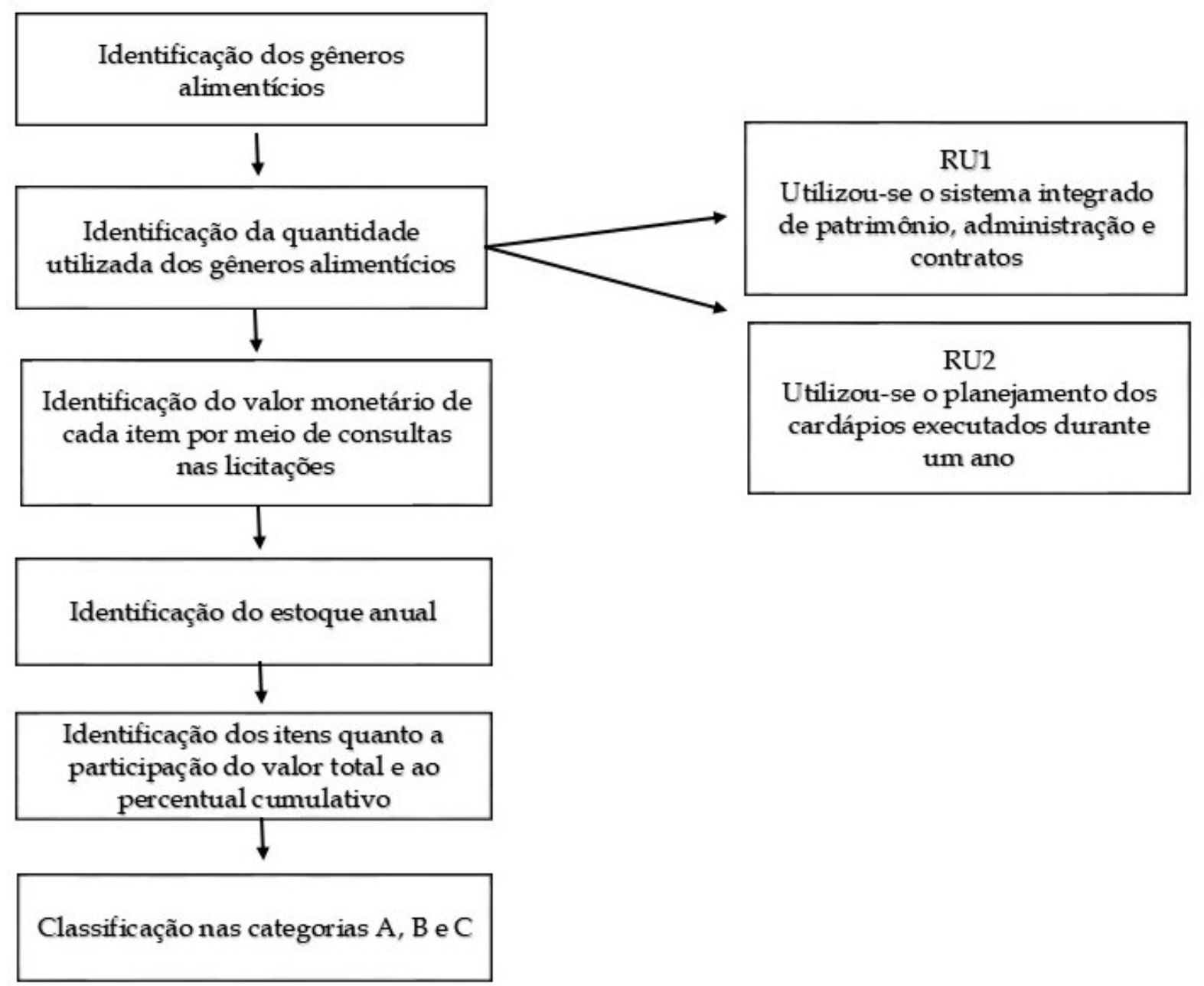

Fonte: Dados da pesquisa.

O consumo e custo anual dos gêneros alimentícios do RU1 e RU2 foram organizados em planilhas no software Microsoft ${ }^{\circledR}$ Excel versão 2010 para auxiliar nos cálculos e elaboração da curva $\mathrm{ABC}$ de maneira a subsidiar a estatística descritiva. Estas planilhas continham os seguintes cálculos: participação (em percentual) de cada um dos itens, o qual foi obtido dividindo o valor total por produto anual pelo gasto total das unidades com gêneros alimentícios; e percentual acumulado, o qual somouos percentuais de participação de um produto ao outro anterior chegando assim ao tal de $100 \%$ ao final de todos os itens.

Dessa forma, as duas colunas finais apresentavam o valor acumulado e a sificação de cada gênero alimentício na curva foi feita no próprio software, ou seja, 


\section{ciência
piural}

itens com percentual acumulado até $80 \%$ foram classificados como classe A, entre $80,01 \%$ e $95 \%$ classe B e entre $95,01 \%$ a $100 \%$ C.

\section{Resultados}

A partir da análise dos cardápios fornecidos pelas empresas tornou-se possível a identificação de 198 gêneros alimentícios presentes no estoque do RU1 e 111 gêneros alimentícios presentes no estoque do RU2. O método utilizado pelas unidades para a realização do controle de estoque é o PEPS, permitindo uma alta rotatividade dos insumos, de modo a evitar que fiquem impróprios para o consumo, elevando consequentemente o custo da produção.

Dessa maneira, as Tabelas 1 e 2 apresentam a síntese dos gêneros analisados no RU1 e RU2, respectivamente, de modo a exemplificar os dez primeiros itens de cada classificação da curva para facilitar a compreensão das informações. 
Tabela 1 - Custos dos gêneros alimentícios, Restaurante Universitário 1, Natal-RN, 2018.

\begin{tabular}{|c|c|c|c|}
\hline GÊNERO ALIMENTÍCIO & $\begin{array}{l}\text { PERCENTUAL } \\
\text { INDIVIDUAL }\end{array}$ & $\begin{array}{l}\text { PERCENTUAL } \\
\text { ACUMULADO }\end{array}$ & CLASSIFICAÇÃO \\
\hline Carne bovina & $19,84 \%$ & $19,84 \%$ & \multirow{11}{*}{$\Lambda$} \\
\hline Carne de sol & $13,12 \%$ & $32,96 \%$ & \\
\hline Coxa e sobrecoxa de frango congelado & $4,83 \%$ & $37,79 \%$ & \\
\hline Filé de peito de frango & $4,58 \%$ & $42,37 \%$ & \\
\hline Peito de frango de $1^{\circ}$ qualidade (3007) & $4,53 \%$ & $46,90 \%$ & \\
\hline Carne de porco, tipo lombo & $4,45 \%$ & $51,35 \%$ & \\
\hline Arroz parboilizado & $2,22 \%$ & $53,57 \%$ & \\
\hline Leite em pó integral instantâneo & $2,21 \%$ & $55,78 \%$ & \\
\hline Leite integral pasteurizado & $1,58 \%$ & $57,36 \%$ & \\
\hline Açúcar refinado triturado & $1,48 \%$ & $58,84 \%$ & \\
\hline Outros alimentos & $20,89 \%$ & $79,72 \%$ & \\
\hline Manteiga comum om sal & $0,62 \%$ & $80,34 \%$ & \\
\hline Alface & $0,60 \%$ & $80,95 \%$ & \\
\hline Alho triturado sem sal & $0,56 \%$ & $81,51 \%$ & \\
\hline Pão criolo & $0,56 \%$ & $82,07 \%$ & \\
\hline Flocos de cereais & $0,55 \%$ & $82,62 \%$ & \\
\hline Pão francês & $0,54 \%$ & $83,16 \%$ & \\
\hline Ovo de galinha & $0,54 \%$ & $83,70 \%$ & \\
\hline Melão japonês & $0,53 \%$ & $84,23 \%$ & \\
\hline Polpa de fruta - acerola & $0,52 \%$ & $84,75 \%$ & \\
\hline Pão redondo & $0,52 \%$ & $85,27 \%$ & \\
\hline Outros alimentos & $9,64 \%$ & $94,91 \%$ & \\
\hline Molho vegetal, tipo inglês & $0,14 \%$ & $95,05 \%$ & \\
\hline Óleo vegetal comestível - tipo soja & $0,14 \%$ & $95,19 \%$ & \\
\hline Molho de soja & $0,14 \%$ & $95,32 \%$ & \\
\hline Farinha de trigo com fermento & $0,14 \%$ & $95,46 \%$ & \\
\hline Rúcula & $0,13 \%$ & $95,59 \%$ & \\
\hline Ervilha verde, em conserva & $0,13 \%$ & $95,72 \%$ & \\
\hline Molho de tomate refogado & $0,13 \%$ & $95,84 \%$ & \\
\hline Óleo de soja & $0,13 \%$ & $95,97 \%$ & \\
\hline Bife hambúrguer de carne bovina & $0,12 \%$ & $96,09 \%$ & \\
\hline Brócolis congelado & $0,12 \%$ & $96,21 \%$ & \\
\hline Outros alimentos & $3,78 \%$ & $100,00 \%$ & \\
\hline
\end{tabular}

Fonte: Dados da pesquisa. 


\section{ciência plural}

Tabela 2 - Custos dos gêneros alimentícios, Restaurante Universitário 2, Santa CruzRN, 2018.

\begin{tabular}{|c|c|c|c|}
\hline GÊNERO ALIMENTÍCIO & $\begin{array}{l}\text { PERCENTUAL } \\
\text { INDIVIDUAL }\end{array}$ & $\begin{array}{l}\text { PERCENTUAL } \\
\text { ACUMULADO }\end{array}$ & CLASSIFICAÇÃO \\
\hline Carne bovina & $13,45 \%$ & $13,45 \%$ & \\
\hline Carne de sol & $10,20 \%$ & $23,65 \%$ & \\
\hline Leite Integral & $7,25 \%$ & $30,90 \%$ & \\
\hline Filé de Frango & $5,62 \%$ & $36,52 \%$ & \\
\hline Filé de Merluza & $3,50 \%$ & $40,01 \%$ & \\
\hline Queijo Muçarela & $3,31 \%$ & $43,32 \%$ & \\
\hline Pão francês & $3,31 \%$ & $46,63 \%$ & \\
\hline Batata inglesa & $2,65 \%$ & $49,28 \%$ & \\
\hline Coxa e sobrecoxa de frango & $2,48 \%$ & $51,76 \%$ & \\
\hline Sardinha & $2,33 \%$ & $54,09 \%$ & \\
\hline Outros Alimentos & $25,64 \%$ & $79,73 \%$ & \\
\hline Mamão & $0,59 \%$ & $80,32 \%$ & \\
\hline Laranja & $0,58 \%$ & $80,90 \%$ & \\
\hline Melão & $0,58 \%$ & $81,48 \%$ & \\
\hline Alho & $0,58 \%$ & $82,06 \%$ & \\
\hline Água mineral & $0,58 \%$ & $82,63 \%$ & \\
\hline Açúcar & $0,57 \%$ & $83,20 \%$ & \\
\hline Feijão fradinho & $0,52 \%$ & $83,72 \%$ & \\
\hline Orégano & $0,51 \%$ & $84,23 \%$ & \\
\hline Óleo de soja & $0,51 \%$ & $84,74 \%$ & \\
\hline Peito de frango com osso & $0,50 \%$ & $85,25 \%$ & \\
\hline Outros Alimentos & $9,69 \%$ & $94,94 \%$ & \\
\hline Queijo coalho & $0,24 \%$ & $95,18 \%$ & \\
\hline Extrato de tomate & $0,24 \%$ & $95,42 \%$ & \\
\hline Molho de soja & $0,23 \%$ & $95,65 \%$ & \\
\hline Colorífico & $0,23 \%$ & $95,88 \%$ & \\
\hline Chuchu & $0,22 \%$ & $96,10 \%$ & \\
\hline Ervilha & $0,20 \%$ & $96,30 \%$ & \\
\hline Massa para lasanha & $0,20 \%$ & $96,50 \%$ & \\
\hline Inhame & $0,20 \%$ & $96,69 \%$ & \\
\hline Pão de forma & $0,19 \%$ & $96,89 \%$ & \\
\hline Glucose de milho & $0,19 \%$ & $97,07 \%$ & \\
\hline Outros Alimentos & $2,93 \%$ & $100,00 \%$ & \\
\hline
\end{tabular}

onte: Dados da pesquisa.

Ao analisar as Tabelas 1 e 2 acima percebe-se que as carnes, itens do prato principal, estão presente em ambas unidades na categoria A, assim como o leite. Porém 
o percentual de participação individual no orçamento apresenta-se de maneira percentualmente diferente, ou seja, no RU1 por ser de um porte maior se gasta mais com esses itens do que no RU2. Nas categorias B apresentaram-se gêneros de consumo geral e custo médio como é o caso das frutas, e na categoria $C$ itens de consumo em menores quantidades como os temperos, molhos e alimentos em conserva.

Na Figura 2 observa-se o gráfico de classificação dos insumos nas categorias A, B e C no RU1.

Figura 2 - Representação gráfica da curva $A B C$ do estoque das refeições ofertadas no Restaurante Universitário 1, Natal-RN, 2018.

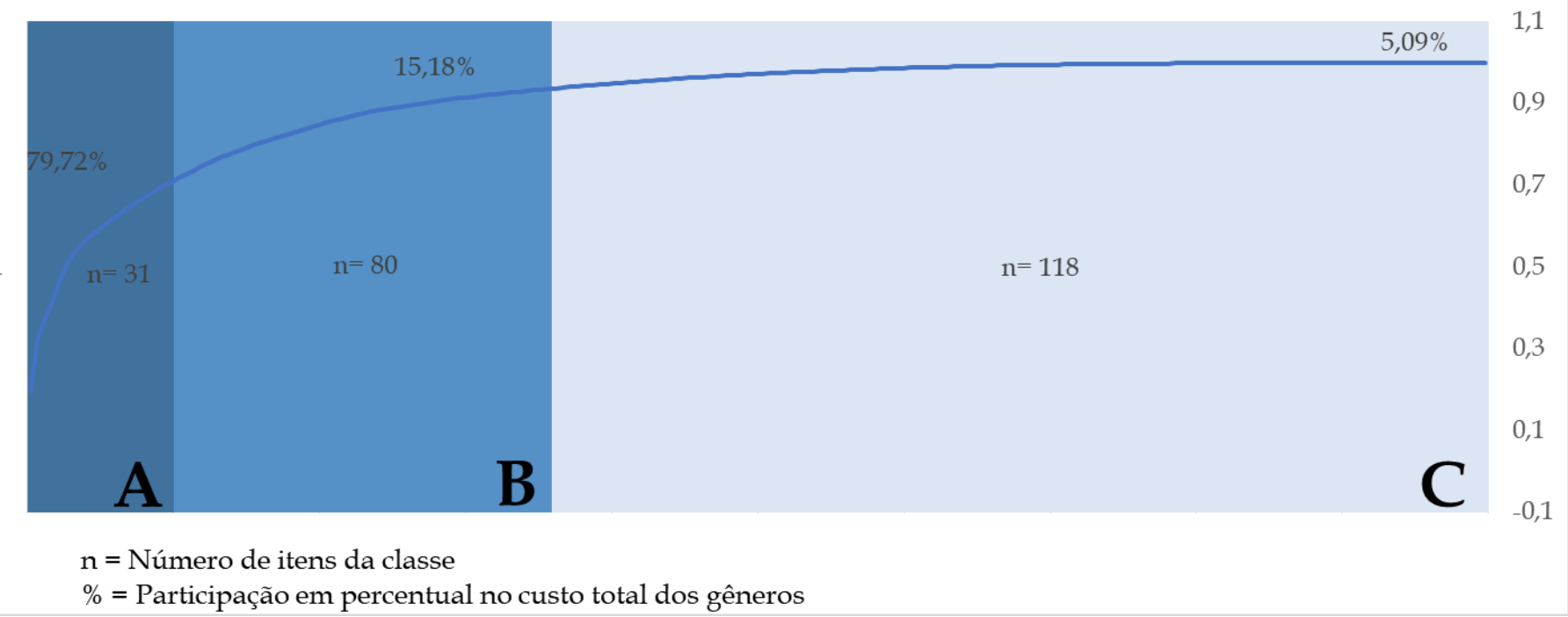

Fonte: Dados da pesquisa.

Os insumos classificados na categoria A representam 15,66\% do total de itens, equivalente a um preço aproximado de $\mathrm{R} \$ 2.590 .919,11$, seguido dos insumos da categoria B que representam 24,75\% dos itens, correspondente a $\mathrm{R} \$ 493.441,06$ e por fim os produtos da categoria $C$ que representam $59,60 \%$ dos itens com preço que equivale a $\mathrm{R} \$ 165.324,73$.

Enquanto que a Figura 3 condiz com os resultados encontrados com a análise realizada no RU2 quanto a classificação dos insumos nas categorias A, B e C. 


\section{ciência plural}

Figura 3 - Representação gráfica da curva $\mathrm{ABC}$ do estoque das refeições ofertadas no Restaurante Universitário 2, Santa Cruz-RN, 2018.

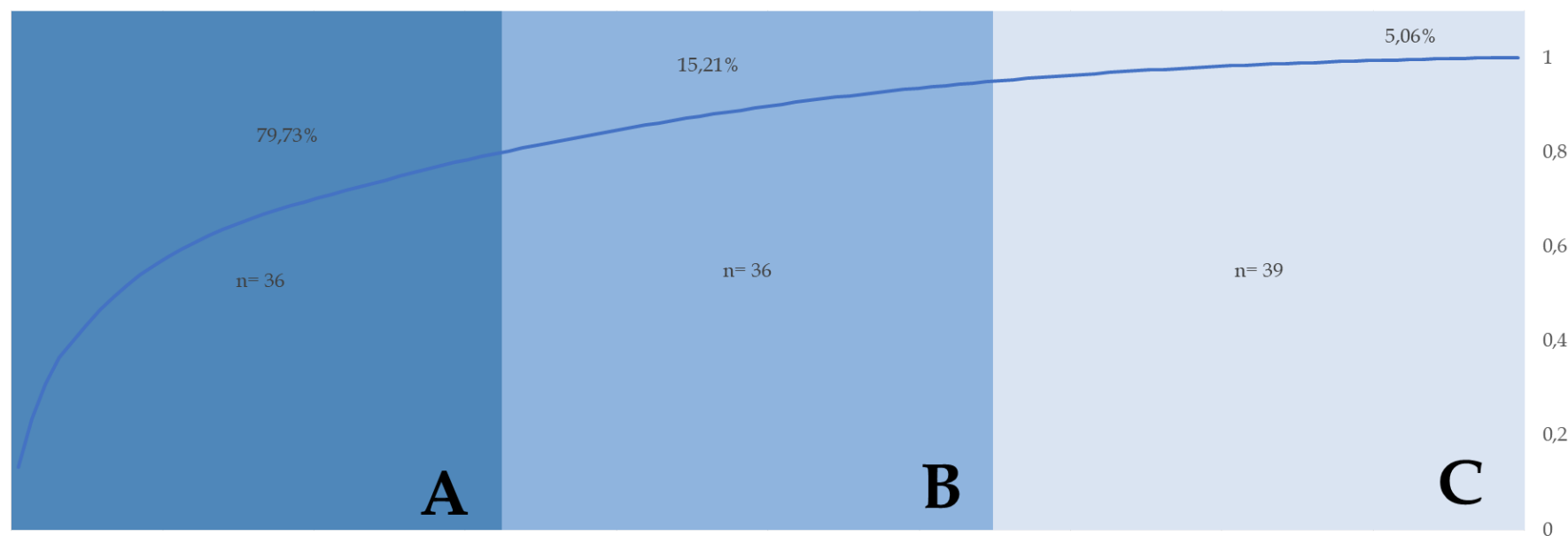

$\mathrm{n}=$ Número de itens da classe

$\%=$ Participação em percentual no custo total dos gêneros

Fonte: Dados da pesquisa.

Tem-se que os insumos classificados na categoria A representam 32,43\% do total de itens do estoque com preço aproximado de $\mathrm{R} \$ 1.699 .904,94$, a categoria B representa 32,4\% do quantitativo dos itens com preço equivalente a $\mathrm{R} \$ 324.298,83$ e a categoria C que corresponde a 35,14\% na contribuição dos itens equivalente a $R$ \$ $107.846,47$.

Diante disso pode-se inferir que as duas unidades institucionais demonstraram menor número de gêneros na classificação A, porém com maior influência monetária, seguidos da classe B e, por fim classe C.

\section{Discussão}

Diante desse cenário, pode-se inferir que as duas unidades demonstraram menor número de gêneros na classificação A, porém com maior influência monetária, seguidos da classe B e por fim, a C. Tais achados são confirmados na pesquisa realizada em uma microempresa alimentícia, a qual encontrou quantidade decrescente de êneros na classificação ABC. Além disso, a ordem de influência financeira e cessidade de maior recurso também está na primeira classe $(A)^{14}$. 
Portanto, ter acesso às informações fornecidas por essa ferramenta dá ao nutricionista ou outro profissional responsável pelo gerenciamento de serviços de alimentação uma importante colaboração na tomada de decisão, visto que o objetivo principal desse sistema de informação está em garantir a qualidade do fluxo de informações e agilizar na tomada de decisão ${ }^{15}$.

Com isso, o planejamento dos gêneros é um exemplo de como a curva $A B C$ pode auxiliar ao gestor nesse processo decisório, uma vez que os produtos e matérias primas a serem utilizados são escolhidos e licitados anualmente, principalmente em unidades institucionais. E a palavra decisão se torna bem difícil quando não há um panorama de como se comportaram a utilização desses insumos, o qual é feito com base no consumo e atendimento do ano anterior, restringido pelo orçamento disponível deliberado pela instância superior. Logo, a curva ABC contribui para essa análise e aplicação correta dos recursos ${ }^{16,17}$.

Atrelado a isso, a curva $\mathrm{ABC}$ auxilia em um controle de custos adequado, ponto crucial para o funcionamento de várias instituições alimentícias, inclusive as de ordem pública como no caso dos RU. Nestes estabelecimentos os orçamentos anuais disponibilizados requerem das organizações e da gestão um discernimento criterioso sobre os gêneros necessários, visto seu alto custo e a variação do custo de acordo com o cardápio para seu eficaz funcionamento no ano subsequente ${ }^{16,18}$.

Desse modo, a ferramenta curva ABC foi implantada para que o fluxo produtivo que acontece desde o recebimento à linha de distribuição, sejam otimizados e com menos perdas econômicas para o serviço, já que a partir do momento onde se tem conhecimento de cada classe de alimentos pode-se ter um olhar diferenciado dos cuidados necessários na manipulação e conservação dos gêneros ${ }^{19}$.

Os itens encontrados em ambos RU na classificação A foram predominantemente os gêneros que compõem os pratos principais como: cortes de frango (peito, filé, coxa e sobrecoxa), carne bovina e peixe. Tal fato pode ser justificado, is são itens que apresentam elevado custo de aquisição, além de estarem presentes grandes refeições por serem fonte predominantemente de proteína. Além do custo compra ser maior, comparado com os outros itens do cardápio, esse valor pode 
aumentar em caso de falhas na qualidade da produção, como um excesso de aparas que serão descartadas ou preparações com baixo rendimento ${ }^{20}$.

Ademais, foi observado que haviam gêneros presentes em mais de uma refeição no dia como: pão, café, polpas de frutas e leite. Em particular o leite apresentou um cenário diferente comparando aos dois RU, pois no RU1 ele apresentou percentual de participação acumulada na curva de $57 \%$, enquanto que no segundo foi de $31 \%$. Isso ocorreu possivelmente devido à presença desse item nas três refeições dessa unidade, inclusive no almoço, já que se trata de um restaurante de maior porte, com linha de distribuição exclusiva para ovolactovegetarianos. Por isso, há utilização predominante desse gênero nas preparações proteicas para esse público, enquanto que na outra unidade a presença desses comensais é praticamente nula ${ }^{10}$.

Aliado a isso, destaca-se o fato de que por mais que a curva ABC utilize do consumo anual dos gêneros, esse é apenas um fator que pode influenciar o controle de um item, pois pode-se citar ainda como interferentes os cuidados de armazenagem, tipo de preparações, custo pela falta do gênero e mudanças de projeto, sendo necessário cautela na generalização dos resultados sem diminuir a importância da classificação ABC para o controle do estoque ${ }^{17}$.

Ainda, frutas como melão e laranja, arroz polido e jerimum foram os gêneros que se classificaram como B, nas duas curvas. Possivelmente por serem de custo médio no pedido de compra e estarem presentes em preparações específicas como o arroz de leite que faz uso do arroz polido. Já no item C, foram encontrados produtos semelhantes para as duas UAN, como extrato de tomate, sal, molho de soja, colorífico e ervilha em conserva. Pode-se associar isso ao fato de que são produtos utilizados em menor quantidade, no intuito de melhorar aspectos sensoriais como sabor e aparência, apresentando baixa influência financeira no custo-refeição.

Nos RU as preparações dos pratos principais são tidas como preferidas pelos comensais ${ }^{21}$ e, por os gêneros que as compõem estarem na classificação A da curva, urge o alerta para a necessidade de um olhar mais acurado sobre a compra e cessamento desses alimentos para que falhas ocultas no custo da produção sejam nimizados tornando-a suficientemente eficiente. 
Isso salienta ainda mais os impactos negativos da falta de um controle na produção, de modo que itens de classificação A outrora citados, apresentam maior criticidade, ou seja, maior impacto no desenrolar das atividades da UAN, uma vez que são cruciais para as preparações, além de interferirem na satisfação da clientela e trazerem em si maior dificuldade de reposição ${ }^{19}$.

Diante disso, a Curva ABC torna-se visivelmente uma excelente estratégia para permitir o conhecimento do padrão das instituições por parte de seus gestores, através de uma visão holística sobre empecilhos que afetam a maximização dos resultados devido a erros na aplicabilidade dos recursos financeiros e, em se tratando da restrição orçamentária desses restaurantes ${ }^{22}$.

Ao comparar as Figuras 2 e 3, pode-se deduzir que a quantidade dos gêneros influenciou a curvatura da imagem, quando se relaciona ao quantitativo de cada classificação. Ademais, como o RU1 dispõe de um número de refeições produzidas superior ao RU2, a divisão dos insumos na curva tornou-se mais visível e significante. Assim sendo, apesar das duas UAN responderem em síntese na mesma direção do preconizado por estudos, o porte de cada uma resultou em diferença de resultados e, consequentemente, apresentação na curva.

Diante desse complexo cenário, é requerido do nutricionista que opera na gestão de serviços de alimentação, atribuições em diferentes níveis de aptidões tais como liderança, gerenciamento e administração ${ }^{23}$. Consequentemente, para auxiliar na sua atuação é fundamental que apresente constante aprimoramento dos processos operacionais. Um exemplo que contribui nesse mecanismo é o uso da classificação $A B C$, além de ser um método de baixo custo de aplicação, mostra-se como eficiente. Dessa forma, em associação com outras ferramentas utilizadas como as fichas técnicas de preparação e o receituário padrão, o custeio $\mathrm{ABC}$ permitirá uma maior agregação de valor em nível gerencial.

Como limitações deste estudo apresenta-se a insuficiente investigação lacionada ao custeio por meio da ferramenta $A B C$, sobretudo em unidades de mentação e nutrição, o que limita a discussão dos achados e possivelmente pode ser indicativo para a baixa aplicação dessa ferramenta em UAN. De tal maneira, 
sugere-se que outras pesquisas sejam realizadas na área para maior aprofundamento da temática e auxilie na administração eficaz dessas entidades.

\section{Conclusões}

A partir da elaboração e análise das curvas $A B C$ nesse estudo, entende-se que as duas unidades por terem portes e cardápios diferentes apresentaram algumas divergências na composição dos itens de cada categoria. No entanto prevaleceu na categoria A de ambas as unidades um menor número de itens, os quais eram prioritariamente proteicos e com maior custo. Esse fato indica que para o gerenciamento adequado de serviços de alimentação é necessário um controle de custos eficiente, o qual necessita da aplicação de sistemas de análise sobre as informações gerenciais disponibilizadas, como a curva $\mathrm{ABC}$.

Este método mostrou auxiliar no processo decisório, pois expressa a qualidade monetária por meio do cuidado com o estoque de alto valor agregado, permitindo focalizar o olhar dos gestores em falhas que afetam a produtividade e a gestão financeira. Dessa maneira, é possível a identificação de pontos críticos, traçar suas melhorias e assim promover melhores resultados nos serviços de alimentação, com apresentação de retorno satisfatório e de qualidade através da definição de metas e mensuração de desempenho.

\section{Referências}

1. Moori RG, Perera LCJ, Mangini ER. Uma análise investigativa do efeito chicote na cadeia de suprimentos da indústria alimentícia. Rev Gestão [Internet]. 2012;18(3):469-88. Available from: http:/ /dx.doi.org/10.5700/rege436.

2. Gervásio MHT. Mensuração de Desempenho Logístico um estudo de casos em quatro empresas Multinacionais atuantes no Brasil. Rio de Janeiro. Dissertação (Mestrado em administração). Instituto COPPEAD de Administração, Universidade Federal do Rio de Janeiro-COPPEAD/UFRJ. 2004.

Dandaro F, Martello LL. Planejamento e controle de estoque nas Organizações. Gestão Ind. 2015;11(2):170-85. 
4. Vago FRM, Sousa CV, Melo JMC, Lara JE, Fagundes AFA, Sampaio D de O. A importância do gerenciamento de estoque por meio da ferramenta curva abc. Rev Sociais e Humanas 2013;26(3):638-55.

5. Medeiros SMNS, Castro Júnior DFL, Deluca MAM, Abreu JC, Martino FA. Gestão de materiais nos restaurantes tipo self service. Revista Eletrônica Científica do CRA-PR 2018;5(1): 81-92.

6. Staevie E, Antunes MT, Souza MA. Análise de custos e resultado em um restaurante comercial. Caderno pedagógico, Lajeado 2015; 12 (1): 124-136.

7. Silva MFN, Carvalho MB. A gestão de compras e o processo de licitação no setor público. Caderno de graduação ciências humanas e sociais. Aracaju 2017; 4 (1): 165178.

8. Vago FRM, Souza CV, Melo JMC. A importância do gerenciamento do estoque por meio da ferramenta curva ABC. Revista Sociais e humanas, Santa Maria 2013 set/dez; 26 (3): 638-55.

9. Almeida DS, Silva JD, Souza AD. Análise da gestão de estoque de uma microempresa de autopeças de Campo Mourão-PR: uso da classificação ABC dos materiais. Revista FOCO 2015 jan./jul;8(1):21-38.

10. Silva LA, Araújo GMB, Carneiro TDC, Araújo PPP. Compreendendo os itens de maior rotatividade de uma mpe do setor gastronômico através da curva abc: estudo de caso no restaurante ponto certo em Caicó/RN. Rev Livre Sustentabilidade e Empreendedorismo 2018;3(2):97-135.

11. Prodanov CC, Freitas EC. metodologia do trabalho científico [recurso eletrônico]: Métodos e Técnicas da Pesquisa e do Trabalho Acadêmico. 2 ed. Novo Hamburgo: Feevale, 2013.

12. BRASIL. Ministério da Saúde. Conselho Nacional de Saúde. Resolução n. 466, de 12 de dezembro de 2012. Aprova diretrizes e normas regulamentadoras de pesquisas envolvendo seres humanos. Brasília, Diário Oficial da União, 12 dez. 2012.

13. BRASIL. Ministério da Saúde. Conselho Nacional de Saúde. Resolução no 510 , de 7 de abril de 2016. Dispõe sobre as normas aplicáveis a pesquisas em Ciências Humanas Sociais. Brasília, Diário Oficial da União, 7 de abr. 2016.

Catarino FRS, Santos MA, Gontijo TS, Rodrigues AC. Gestão de estoque em na microempresa do ramo alimentício: comparação entre a Curva ABC e o Método Z". Revista Caribeña de Ciencias Sociales, 2017 abril. 
15. Jeronimo GP, Dittrich MT. A importância do controle de estoques em uma empresa de material de construção. Santa Catarina. Trabalho de Conclusão de Curso (Graduação em administração). Faculdade Capivari, 2012.

16. Calazans DLMS, Neto MVS, Araújo FR. Sistemas de informação como ferramenta gerencial na análise de custos das refeições produzidas em uma unidade de alimentação e nutrição pública. In: Anais do I Congresso internacional de desempenho do setor público; 2017 set 4-6; Florianópolis (SC). Florianópolis: I CIDESP. 2017. p. 2252- 2267.

17. Oliveria CM. Curva $\mathrm{ABC}$ na gestão de estoque. In: III Encontro científico e simpósio de educação Unisalesiano. 2011 out 17 - 21; Lins (SP). Lins: Unisalesiano. 2011. p. 1-14.

18. Pereira, LCA; Flor, TBM; Calazans, DLMS. Gestão de custos no serviço público: proposta de metodologia para análise e controle em Unidades de Alimentação e Nutrição. Revista Ciência Plural 2019; 5(2):32-48.

19. Simões L, Ribeiro MC. A curva ABC como ferramenta para análise de estoques. In: I Encontro científico e I simpósio de educação Unisalesiano. 2007 out 17 - 20; Lins (SP). Lins: Unisalesiano. 2007. p. 1-9.

20. Carvalho ACMS, Cabral HCC, Morais MP. Composição nutricional e custo de preparações de restaurantes por peso. Revista Demetra 2013;8(1):23 - 38.

21. Araújo CL, Pires FM, Lourenço MS, Carvalho LR. Avaliação quantitativa dos copos descartáveis e restos alimentares gerados pelos usuários de um restaurante universitário no Estado do Rio de Janeiro. Revista Demetra 2018;13(4); 767-782.

22. Morais GM, Santos VF, Neto MTR. Gestão de custos no setor público: um estudo em restaurante universitário. Revista Brazilian Journal of Development 2019; 5(3):1913 - 1933.

23. Sartor J, Alves MK. Percepção do perfil de liderança do nutricionista gestor em unidades de alimentação e nutrição. Revista Saúde e Desenvolvimento Humano 2019 out;7(3):13-19. 